\title{
PENGARUH LINGKUNGAN KERJA DAN STANDAR OPERASIONAL PROSEDUR TERHADAP PRODUKTIVITAS KERJA KARYAWAN PENGAWAS URUSAN GERBONG SUKACINTA (PUG SCT) PT. KERETA API INDONESIA (PERSERO) KABUPATEN LAHAT
}

Yayan Darmayanti

STIE Serelo Lahat - Sumatera yayandarmayanti@gmail.com

\begin{abstract}
This study aims to determine the effect of the work environment on productivity, the effect of operational standards on the procedure against productivity in the supervisor of the affairs of gerbongsukacinta (PUG SCT) PT. Kereta Api Indonesia (Persero) of Lahat Regency. The research method in this research is quantitative, descriptive, instrument test (validity and reliability), Classic assumption and Intrensial Statistic Analysis (Model Compatibility Test / Multiple Regression, Coefficient of determination, correlation coefficient, $T_{\text {test }}$ and $F_{\text {test }}$ ). Provide explanations relating to issues based on Human Resources management theories. From the result of calculation of multiple regression analysis in this research, the equation values are: $Y=1.715+0.854 X 1+0.135$ $X_{2}$ means that the working environment and standard operational procedures have a positive effect in productivity, the coefficient of determination $(K D)=$ $84.3 \%$ is influenced by work environment and Standard operating procedures and the remaining $15.7 \%$ influenced by other factors not discussed in this study, the results of the calculation of correlation coefficient analysis obtained $r$ value of 0.921 (close to 1), meaning that the work environment and standard operating procedures have a positive and very influence Strongly against productivity, test results $T_{\text {test }}$ that variables $X_{1}$ (work environment) and $X_{2}$ (standard operational procedures) have a partial effect on variable $Y$ (productivity), and $F_{\text {test }}$ obtained $p$-value of 0.000 smaller than alpha value is 0,05 then the working environment variables and operational standards of the procedure simultaneously $N$ effect on employee productivity. So this hypothesis is proven.
\end{abstract}

Keywords: Work Environment, Standard Operating Procedures and Productivity 


\section{ABSTRAK}

Penelitian ini bertujuan untuk mengetahui pengaruh lingkungan kerja terhadap produktivitasi, pengaruh standar operasional prosedur terhadap terhadap produktivitas pada pengawas urusan gerbongsukacinta(PUG SCT) PT. Kereta Api Indonesia (Persero) Kabupaten Lahat.Metode penelitian dalam penelitian ini adalah analisis kuantitatif, Deskriptif, Uji Instrumen (validitas dan reliabilitas), Asumsi Klasik dan Analisis Statistik Intrensial (Uji Kesesuaian Model/Regresi Berganda, Koefisien determinasi, koefisien korelasi, uji T dan Uji F).Dan analisis Kualitatif yang memberikan penjelasan yang berhubungan dengan permasalahan yang didasarkan pada teori-teori manajemen Sumber Daya Manusia. Dari hasil perhitungan analisa regresi berganda pada penelitian ini didapat nilai persamaan : $\mathrm{Y}=1.715+0.854 \mathrm{X} 1+0.135 \mathrm{X} 2$ berarti bahwa lingkungan kerja dan standar operasional prosedur berpengaruh positif dalam produktivitas, besarnya koefisien determinasi $(K D)=84,3 \%$ dipengaruhi oleh lingkungan kerja dan standar operasional prosedur dan sisa nya 15,7 \% dipengaruhi oleh faktor lain yang tidak dibahas dalam penelitian ini, hasil dari perhitungan analisa koefisien korelasi didapat nilai $r$ sebesar 0.921 (mendekati 1), artinya lingkungan kerja dan standar operasional prosedur mempunyai pengaruh yang positif dan sangat kuat terhadap produktivitas, hasil pengujian uji Tmenerangkan bahwa variabel $X_{1}$ (lingkungan kerja) dan $X_{2}$ (standar operasional prosedur) mempunyai pengaruh parsial terhadap variabel $Y$ (produktivitas), dan uji $\mathrm{F}$ didapat nilai $\mathrm{p}$-valuenya sebesar 0,000 lebih kecil dari nilai alpha yaitu 0,05 maka variabel lingkungan kerja dan standar operasional prosedur secara simultan berpengaruh terhadap produktivitas karyawan.sehingga hipotesis ini terbukti.

Kata kunci: Lingkungan Kerja, Standar Operasional Prosedur Dan Produktivitas

\section{PENDAHULUAN}

Memasuki era globalisasi sekarang ini dan dimasa akan datang kompetisi yang terjadi sudah bersifat global dan adanya perubahan-perubahan kondisi ekonomi menyebabkan banyak perusahaan melakukan langkah perbaikan. Hal ini mendorong terjadinya perubahan pada perusahaan dari biasa-biasa saja menjadi mengikuti perkembangan zaman (I Made, 2011).
Kondisi sebagaimana telah diuraikan harus benar-benar disadari dan dipersiapkan secara sejak dini. Persiapan ini terutama pada masalah sumberdaya manusia yang bermutu dengan kualifikasi yang sesuai dengan perkembangan dunia saat ini (Tjipto, 2010).

Oleh karena itu, produktivitas sumberdaya manusia merupakan hal yang sangat penting di dalam usaha memperbaiki pelayanan kepada masyarakat, sehingga perlu 
diupayakan secara terus menerus dan berkesinambungan dalam menghadapi tuntutan masyarakat.

Berdasarkan survei awal peneliti terhadap tidak sedikit karyawan Pengawas Urusan Gerbong Sukacinta (PUG SCT) yang hanya menggunakan perlengkapan seadanya saja. Atau sekip, tanda berwarna merah yang dipasang di kereta paling belakang, kini tidak berbentuk oval lagi, tetapi sudah beragam, tergantung siapa yang bikin, padahal itu diatur jelas dalam reglement $\mathrm{KA}$.

Oleh karena itu dalam penelitian ini akan dikaji pengaruh lingkungan kerja dan standar operasional prosedur terhadap produktivitas kerja karyawan pada pada Pengawas Urusan Gerbong Sukacinta (PUG SCT) PT. Kereta Api Indonesia (Persero) Kabupaten Lahat.

\section{KAJIANTEORITIK Lingkungan Kerja}

Lingkungan kerja adalah tempat di mana karyawan melakukan aktivitas setiap harinya. Lingkungan kerja yang kondusif memberikan rasa aman dan memungkinkan karyawan untuk dapat bekerja optimal. Lingkungan kerja dapat mempengaruhi emosional karyawan (Sedarmayanthi, 2009).

Jika karyawan menyenangi lingkungan kerja di mana dia bekerja, maka karyawan tersebut akan betah di tempat kerjanya, melakukan aktivitasnya sehingga waktu kerja dipergunakan secara efektif. Produktivitas akan tinggi dan otomatis prestasi kerja karyawan juga tinggi. Lingkungan kerja itu mencakup hubungan kerja antara bawahan dan atasan serta lingkungan fisik tempat karyawan bekerja (Kamus Besar Bahasa Indonesia)."Lingkungan kerja adalah lingkungan dimana pegawai melakukan pekerjaannya seharihari." Lingkungan kerja yang kondusif memberikan rasa aman dan memungkinkan para karyawan untuk dapat berkerja optimal. Lingkungan kerja dapat mempengaruhi emosi karyawan (Sudjana, 2010).

Jika pegawai menyenangi lingkungan kerja dimana dia bekerja, maka karyawan tersebut akan betah di tempat kerjanya untuk melakukan aktivitas sehingga waktu kerja dipergunakan secara efektif dan optimis prestasi kerja karyawan juga tinggi.

Lingkungan kerja tersebut mencakup hubungan kerja yang terbentuk antara sesama karyawan dan hubungan kerja antar bawahan dan atasan serta lingkungan fisik tempat pegawai bekerja. Lingkungan Kerja adalah "Keseluruhan alat pekakas dan bahan yang dihadapi, lingkungan sekitar di mana ia bekerja, metode kerjanya baik perorangan maupun kelompok". (Sedarmayanthi, 2009).

\section{Standar Operasional Prosedur}

Standar Operasional Prosedur (SOP) merupakan dokumen yang berisi langkah-langkah/sistematika kerja dalam sebuah organisasi. Dari beberapa pengertian SOP menurut para ahli, tujuan utama dari penyusunan SOP adalah untuk mempermudah setiap proses kerja 
dan meminimalisir adanya kesalahan di dalam proses pengerjaannya (Koesmono, 2012). Adapun tujuan dari penyusunan SOP diantaranya:

a. Agar petugas atau pegawai menjaga konsisitensi dan tingkat kinerja petugas atau pegawai atau tim dalam organisasi atau unit kerja.

b. Agar mengetahui dengan jelas peran dan fungsi tiap-tiap posisi dalam organisasi.

c. Memperjelas alur tugas, wewenang dan tanggung jawab dari petugas atau pegawai terkait.

d. Melindungi organisasi atau unit kerja dan petugas atau pegawai dari malpraktek atau kesalahan administrasi lainnya.

e. Untuk menghindari kegagalan atau kesalahan, keraguan, duplikasi dan inefisiensi, dan;

f. Memberikan keterangan tentang dokumen-dokumen yang dibutuhkan dalam suatu proses kerja.

\section{Produktivitas Kerja}

Sesuai dengan masalah yang akan dibahas, maka perlu dikemukakan pengertian dari produktivitas menurut beberapa ahli, di antaranya: produktivitas menurut Tohardi (Sutrisno, 2011) mengemukakan bahwa produktivitas kerja merupakan sikap mental.Sikap mental yang selalu mencari perbaikan terhadap apa yang telah ada (Manulang, 2012).

Suatu keyakinan bahwa seseorang dapat melakukan pekerjaan lebik baik hari ini daripada hari kemaren dan hari esok lebik baik hari ini (Sondang, 2014). Pendapat tersebut didukung oleh Ravianto, mengatakan produktivitas pada dasarnya mencakup sikap mental yang selalu mempunyai pandangan bahwa kehidupan hari ini harus lebih baik dari hari kemaren dan hari esok harus lebih baik dari hari ini.

Menurut melayu S.P Hasibuan (Hasibuan, 2011) produktivitas kerja adalah perbandingan antara output dan input, dimana output harus mempunyai nilai tambah dan teknik pekerjaan yang lebih baik.

\section{METODOLOGI PENELITIAN}

Penelitian ini merupakan penelitian diskriptif kuantitatif, yaitu suatu penelitian yang bertujuan untuk mengumpulkan data yang aktual dan akurat, menggambarkan dan menganalisa data tersebut yang berhubungan dengan permasalahan yang diteliti selanjutnya dari hasil analisis ditarik suatu kesimpulan (Sugiono, 2013).

Penelitian ini mengukur tentang kinerja karyawan yang ditinjau dari lingkungan kerja dan standar operasional prosedur pada Pengawas Urusan Gerbong Sukacinta (PUG SCT) PT. Kereta Api Indonesia (Persero) Kabupaten Lahat.

Populasi dan sampel dalam penelitian ini menggunakan metode sensus, yaitu menggambil jumlah keseluruhan dari jumlah karyawan pada Pengawas Urusan Gerbong Sukacinta (PUG SCT) PT. Kereta Api Indonesia(Persero) kabupaten lahat, yaitu sebanyak 50 orang karyawan. 
Adapun teknik pengumpulan data yang digunakan dalam penelitian ini adalah dengan teknik observasi, wawancara dan quisioner.

Teknik analisis yang digunakan dalam penelitian ini adalah analisis deskriptif, uji instrumen (validitas dan reliabilitas), asumsi klasik dan analisis statistik intrensial (uji kesesuaian model/ regresi berganda, koefisien determinasi, koefisien korelasi, uji T dan uji F).

\section{HASILDAN PEMBAHASAN}

Dalam penelitian ini metode yang digunakan adalah analisa kualitatif dan analisa kuantitatif.

Berdasarkan pengumpulan data yang dilakukan oleh penulis pada objek penelitian melalui wawancara dan observasi diketahui tentang pengaruh lingkungan kerja $\left(X_{1}\right)$ dan standar operasional prosedur $\left(X_{2}\right)$ terhadap produktivitas.

Berikut ini adalah hasil penelitian pengaruh lingkungan kerja dan standar operasional prosedur terhadap produktivitas pada Pengawas Urusan Gerbong Sukacinta (PUG SCT) PT. Kereta Api Indonesia (Persero) Kabupaten Lahat.

\section{a. Analisis Deskriptif}

Suatu analisis yang mengambarkan tanggapan responden mengenai lingkungan kerja $\left(X_{1}\right)$, standar operasional prosedur $\left(\mathrm{X}_{2}\right)$ dan produktivitas (Y) yang diperoleh dari hasil jawaban responden.

\section{b. Uji Instrumen}

- Validitas, uji validitas digunakan untuk mengukur sah atau valid tidaknya suatu kuisioner.

Tabel 1. Hasil Uji Validitas Instrumen

\section{No $\begin{gathered}\begin{array}{c}\text { Butir } \\ \text { Pertanyaan }\end{array} \\ \begin{array}{c}\text { Component } \\ \text { Matriks }\end{array}\end{gathered}$ Keterangan}

VariabelLingkungan Kerja $\left(\mathrm{X}_{1}\right)$

\begin{tabular}{c|c|c|c}
\hline 1 & $\mathrm{q} 1 \times 1$ & 0.624 & Valid \\
\hline 2 & $\mathrm{q} 2 \times 1$ & 0.570 & Valid \\
\hline 3 & $\mathrm{q} 3 \times 1$ & 0.787 & Valid \\
\hline 4 & $\mathrm{q} 4 \times 1$ & 0.802 & Valid \\
\hline 5 & $\mathrm{q} 5 \times 1$ & 0.751 & Valid \\
\hline 6 & $\mathrm{q} 6 \times 1$ & 0.665 & Valid \\
\hline 7 & $\mathrm{q} 7 \times 1$ & 0.643 & Valid \\
\hline 8 & $\mathrm{q} 8 \times 1$ & 0.514 & Valid \\
\hline 9 & $\mathrm{q} 9 \times 1$ & 0.576 & Valid \\
\hline 10 & $\mathrm{q} 10 \times 1$ & 0.817 & Valid \\
\hline
\end{tabular}

VariabelStandar Operasional Prosedur $\left(\mathrm{X}_{2}\right)$

\begin{tabular}{c|c|c|c}
\hline 1 & $\mathrm{q} 1 \times 2$ & 0.709 & Valid \\
\hline 2 & $\mathrm{q} 2 \times 2$ & 0.758 & Valid \\
\hline 3 & $\mathrm{q} 3 \times 2$ & 0.812 & Valid \\
\hline 4 & $\mathrm{q} 4 \times 2$ & 0.714 & Valid \\
\hline 5 & $\mathrm{q} 5 \times 2$ & 0.718 & Valid \\
\hline 6 & $\mathrm{q} 6 \times 2$ & 0.775 & Valid \\
\hline 7 & $\mathrm{q} 7 \times 2$ & 0.821 & Valid \\
\hline 8 & $\mathrm{q} 8 \times 2$ & 0.753 & Valid \\
\hline 9 & $\mathrm{q} 9 \times 2$ & 0.600 & Valid \\
\hline 10 & $\mathrm{q} 10 \times 2$ & 0.783 & Valid
\end{tabular}

VariabelProduktivitas (Y)

\begin{tabular}{c|c|c|c}
\hline 1 & q1y & 0.549 & Valid \\
\hline 2 & q2y & 0.611 & Valid \\
\hline 3 & q3y & 0.755 & Valid \\
\hline 4 & q4y & 0.766 & Valid \\
\hline 5 & q5y & 0.717 & Valid \\
\hline 6 & q6y & 0.642 & Valid \\
\hline 7 & q7y & 0.643 & Valid \\
\hline 8 & q8y & 0.581 & Valid \\
\hline 9 & q9y & 0.588 & Valid \\
\hline 10 & q10y & 0.791 & Valid \\
\hline
\end{tabular}

Sumber : pengolahan data, 2017 
Dari tabel di atas dalam pengujian validitas untuk variabel lingkungan kerja,standar operasional prosedurdan produktivitas ternyata dari masing-masing 10 Item pertanyaan yang diujikan semuanya dinyatakan valid karena nilai komponen faktornya > 0,30. Hasil perhitungan validitas instrumen dengan program SPSS.

- Reliabilitas, reabilitas adalah ukuran tingkat ketepatan ketelitian atau keakuratan sebuah instrument sehingga konsistensi instrument yang dinyatakan reliabel jika alat ukur yang digunakan aman karena bekerja dengan baik pada waktu dan kondisi yang berbeda. Hasil uji reliabilitas dalam penelitian ini didapat bahwa cronbachs Alpha dan nilai tersebut $>0.60$ maka variabel dalam penelitian ini dinyatakan reliabel. Tabel 2.

Hasil Uji Reliabilitas Instrument

\begin{tabular}{l|c}
\hline Cronbach's Alpha & Nof Items \\
\hline VariabelLingkungan Kerja (X1) \\
\hline 0.862 & 10 \\
\hline VariabelStandar Operasional Prosedur (X2) \\
\hline 0.910 & 10 \\
\hline VariabelProduktivitas(Y) \\
\hline \multicolumn{2}{c}{0.852} \\
Sumber : pengolahan data, 2017
\end{tabular}

Hasil uji reliabilitas terhadap variabel lingkungan kerja, standar operasional prosedur dan produktivitas, didapat bahwa cronbachs Alpha nilai tersebut > 0.60 maka variabel lingkungan kerja, standar operasional prosedur dan produktivitas dinyatakan reliabel.

\section{c. Uji Normalitas}

Pengujian dilakukan dengan menggunakan grafik scatter plot. Uji normalitas digunakan untuk mengetahui apakah model regresi dalam penelitian ini baik variabel terikat maupun variabel bebas keduanya mempunyai distribusi normal atau tidak. Dapat dilihat pada grafik Q-Q Plot bila titik-titik yang menyebar disekitar garis diagonal serta penyebarannya mengikuti arah garis diagonal, maka data tersebut dapat dikatakan distribusi normal.

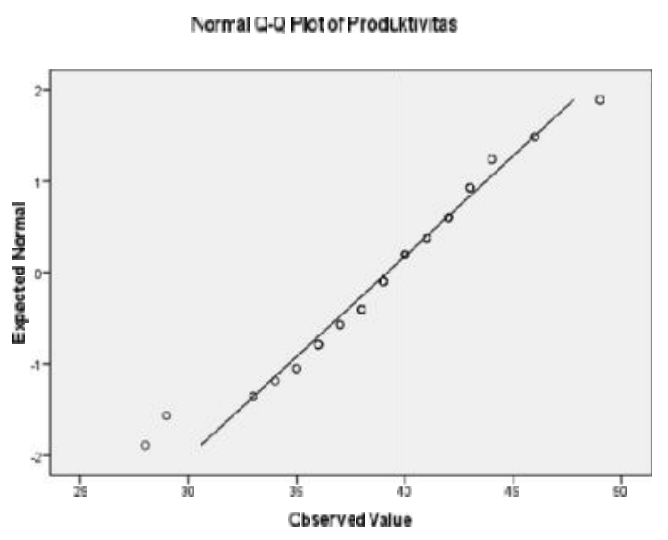

Gambar 1.

Grafik Normal Q-Q Plot

Dependent Variabel Produktivitas

Gambar 1 menunjukan hasil analisis regresi linier dengan grafik normal Q-Q Plot terhadap residual error model regresi diperoleh sudah menunjukan adanya pola grafik yang normal, yaitu adanya sebaran titik yang berada tidak jauh dari garis diagonal.

\section{- Uji Linieritas}

Uji linieritas ini dimaksudkan untuk mengetahui apakah 
model persamaan yang kita

peroleh cocok atau tidak.

Tabel 3.

Hasil Uji Linieritas ANOVA Table

\begin{tabular}{|c|c|c|c|c|c|c|c|}
\hline & & & $\begin{array}{l}\text { Sum of } \\
\text { Squares }\end{array}$ & $d f$ & $\begin{array}{l}\text { Mean } \\
\text { Square }\end{array}$ & $\mathrm{F}$ & Sig. \\
\hline \multirow{5}{*}{$\begin{array}{l}\text { Produktivitas * } \\
\text { Lingkungan } \\
\text { Kerja }\end{array}$} & \multirow[t]{3}{*}{$\begin{array}{l}\text { BetweenGro } \\
\text { ups }\end{array}$} & (Combined) & 914.713 & 15 & 60.981 & 20.596 & 0.000 \\
\hline & & Linearity & 830.379 & 1 & 830.379 & 280.459 & 0.000 \\
\hline & & $\begin{array}{l}\text { Deviation from } \\
\text { Linearity }\end{array}$ & 84.334 & 14 & 6.024 & 2.035 & 0.045 \\
\hline & \multicolumn{2}{|l|}{ Within Groups } & 100.667 & 34 & 2.961 & & \\
\hline & \multicolumn{2}{|l|}{ Total } & 1015.380 & 49 & & & \\
\hline \multirow{5}{*}{$\begin{array}{l}\text { Produktivitas * } \\
\text { Standar } \\
\text { Operasional } \\
\text { Prosedur }\end{array}$} & \multirow[t]{3}{*}{$\begin{array}{l}\text { Between } \\
\text { Groups }\end{array}$} & (Combined) & 465.347 & 17 & 27.373 & 1.593 & 0.125 \\
\hline & & Linearity & 69.703 & 1 & 69.703 & 4.055 & 0.043 \\
\hline & & $\begin{array}{l}\text { Deviation from } \\
\text { Linearity }\end{array}$ & 395.643 & 16 & 24.728 & 1.439 & 0.186 \\
\hline & \multicolumn{2}{|c|}{ Within Groups } & 550.033 & 32 & 17.189 & & \\
\hline & \multicolumn{2}{|l|}{ Total } & 1015.380 & 49 & & & \\
\hline
\end{tabular}

Sumber : pengolahan data, 2017

Hasil pengujian antara produktivitas dan lingkungan kerja menunjukan bahwa nilai signifikan pada Linearity sebesar 0.000 , serta antara produktivitas dan standar operasional prosedur menunjukan bahwa nilai signifikan pada Linearity sebesar 0.043, karena signifikan kurang dari 0.05 maka dapat disimpulkan bahwa antara variabel lingkungan kerja, standar operasional prosedur dan produktivitas terdapat hubungan yang linier. Dengan ini maka asumsi linieritas terpenuhi.

\section{Analisis Statistik Intrensial}

- Uji Kesesuaian Model (Regresi Berganda)

Untuk mengetahui pengaruh variabel Lingkungan Kerja $\left(X_{1}\right)$, Standar Operasional Prosedur $\left(\mathrm{X}_{2}\right)$ secara bersama-sama terhadap Produktivitas Kerja (Y). Tabel 4. Hasil Analisis Regresi Berganda Coefficients ${ }^{\mathrm{a}}$

\begin{tabular}{|c|c|c|c|c|c|c|}
\hline & \multirow[t]{2}{*}{ Model } & \multicolumn{2}{|c|}{$\begin{array}{c}\text { Unstandardized } \\
\text { Coefficients }\end{array}$} & \multirow{2}{*}{\begin{tabular}{|c|}
$\begin{array}{c}\text { Standardized } \\
\text { Coefficients }\end{array}$ \\
Beta \\
\end{tabular}} & \multirow[t]{2}{*}{$\mathrm{t}$} & \multirow[t]{2}{*}{ Sig. } \\
\hline & & $B$ & Std. Error & & & \\
\hline \multirow[t]{3}{*}{1} & (Constant) & 1.715 & 2.531 & & 0.677 & 0.501 \\
\hline & Lingkungan Kerja & 0.854 & 0.055 & 0.887 & 15.586 & 0.000 \\
\hline & Standar Operasional Prosedur & 0.135 & 0.043 & 0.178 & 3.118 & 0.003 \\
\hline
\end{tabular}

Sumber : pengolahan data, 2017

Dari tabel di atas didapat $0.135 \mathrm{X} 2$, persamaan regresi persamaan $Y=1.715+0.854 \times 1+$ tersebut dapat dilihat variabel 
linkungan kerja yang paling dominan berpengaruh karena nilai koefisien regresinya paling besar yaitu 0.854 dan variabel standar operasional prosedur sebesar 0.135 - Koefisien Determinasi
Analisis ini digunakan untuk mengetahui seberapa besar sumbangan yang diberikan variabel bebas terhadap variabel terikat yang yg ditunjukan dalam prosentase.

Tabel 5. Hasil Analisis Koefisien Determinasi Model Summary

\begin{tabular}{c|c|c|c|c}
\hline Model & $\mathrm{R}$ & $\mathrm{R}$ Square & Adjusted R Square & $\begin{array}{c}\text { Std. Error of the } \\
\text { Estimate }\end{array}$ \\
\hline 1 & $0.921^{\mathrm{a}}$ & 0.849 & 0.843 & 1.80602 \\
\hline
\end{tabular}

Sumber : pengolahan data, 2017

Dari tabel di atas 0.843 berarti sebesar $84,3 \%$ dipengaruhi oleh variabel lingkungan kerja dan standar operasional prosedur, serta sisanya sebesar $15,7 \%$ dipengaruhi oleh variabel lain yang tidak masuk dalam penelitian ini.

- Koefisien Korelasi
Untuk mengetahui seberapa kuat hubungan antara variabel bebas dengan variabel terikat dapat diketahui dengan besarnya koefisien korelasi.Nilai koefisien korelasi antara -1 sampai 1.ukuran korelasi (r) antara variabel yang kuat dan tinggi.

Tabel 6. Hasil Analisis Koefisien Korelasi Model Summary

\begin{tabular}{c|c|c|c|c}
\hline Model & $\mathrm{R}$ & R Square & Adjusted R Square & Std. Error of the Estimate \\
\hline 1 & $0.921^{\mathrm{a}}$ & 0.849 & 0.843 & 1.80602 \\
\hline
\end{tabular}

Sumber : pengolahan data, 2017

Dari tabel di atas menunjukan 0.921 berarti lingkungan kerja dan standar operasional prosedur mempunyai hubungan yang sangat kuat terhadap produktivitas karyawan pada Pengawas Urusan Gerbong Sukacinta (PUG SCT) PT. Kereta Api Indonesia (Persero) Kabupaten Lahat.

\section{Uji T}

Digunakan untuk mengetahui signifikai ada tidaknya pengaruh variabel bebas terhadap variabel terikat secara parsial atau sendiri-sendiri, sehingga sudah diketahui apakah dugaan yang sudah ada dapat diterima atau ditolak 
Tabel 7. Hasil Analisis Uji T Coefficients $^{\mathrm{a}}$

\begin{tabular}{|c|c|c|c|c|c|c|}
\hline & \multirow[t]{2}{*}{ Model } & \multicolumn{2}{|c|}{$\begin{array}{c}\text { Unstandardized } \\
\text { Coefficients }\end{array}$} & \multirow{2}{*}{$\begin{array}{c}\text { Standardized } \\
\text { Coefficients } \\
\text { Beta }\end{array}$} & \multirow[t]{2}{*}{$\mathrm{t}$} & \multirow[t]{2}{*}{ Sig. } \\
\hline & & $\mathrm{B}$ & Std. Error & & & \\
\hline \multirow[t]{3}{*}{1} & (Constant) & 1.715 & 2.531 & & 0.677 & 0.501 \\
\hline & Lingkungan Kerja & 0.854 & 0.055 & 0.887 & 15.586 & 0.000 \\
\hline & Standar Operasional Prosedur & 0.135 & 0.043 & 0.178 & 3.118 & 0.003 \\
\hline
\end{tabular}

Sumber : pengolahan data, 2017

Dari tabel di atas, pengujian hipotesis ini secara parsial terbukti berpengaruh terhadap variabel terikat.

- Uji F

Uji $F$ digunakan untuk mengetahui signifikan pengaruh variabel Lingkungan Kerja $\left(\mathrm{X}_{1}\right)$ dan Standar Operasional Prosedur $\left(\mathrm{X}_{2}\right)$ secara bersamasama terhadap Produktivitas $\operatorname{Kerja}(\mathrm{Y})$.

Tabel 8. Hasil Analisis Uji F ANOVA ${ }^{\mathrm{b}}$

\begin{tabular}{c|c|c|c|c|c|c}
\hline \multicolumn{2}{c|}{ Model } & Sum of Squares & df & Mean Square & F & Sig. \\
\hline \multirow{3}{*}{1} & Regression & 862.080 & 2 & 431.040 & 132.152 & $0.000^{\mathrm{a}}$ \\
\cline { 2 - 7 } & Residual & 153.300 & 47 & 3.262 & & \\
\cline { 2 - 7 } & Total & 1015.380 & 49 & & & \\
\hline
\end{tabular}

Sumber : pengolahan data, 2017

Dari tabel di atas, didapat nilai p-valuenya sebesar 0,000 lebih kecil dari nilai alpha yaitu 0,05 maka variabel lingkungan kerja dan standar operasional prosedur secara simultan berpengaruh terhadap produktivitas karyawan.

\section{KESIMPULAN DAN SARAN}

Lingkungan kerja memiliki pengaruh yang besar terhadap produktivitas karena lingkungan kerja merupakan suatu lingkungan di mana karyawan bekerja, sedangkan kondisi kerja merupakan kondisi dimana karyawan tersebut bekerja, dan tentunya dengan lingkungan kerja yang baik maka akan menimbulkan pedoman atau acuan untuk melaksanakan tugas pekerjaan sesuai denga fungsi dan alat penilaian kerja, berdasarkan indikator-indikator teknis, administratif dan prosedural sesuai tata kerja, prosedur kerja dan sistem kerja pada unit kerja yang bersangkutan.

Mengingat bahwa lingkungan kerja merupakan variabel yang paling dominan berpengaruh terhadap kinerja, maka disarankan agar lebih memperhatikan lingkungan kerja baik fisik maupun non fisik dimaksudkan agar peran lingkungan kerja dapat memberikan rasa aman dan nyaman bagi setiap karyawan. 
Disarankan pula hendaknya Pengawas Urusan Gerbong Sukacinta (PUG SCT) PT. Kereta Api Indonesia (Persero) Kabupaten Lahat, untuk lebih memperhatikan standar operasional prosedur karena itu merupakan suatu pedoman atau acuan untuk melaksanakan tugas pekerjaan sesuai denga fungsi dan alat penilaian kerja, berdasarkan indikator-indikator teknis, administratif dan prosedural sesuai tata kerja, prosedur kerja dan sistem kerja pada unit kerja yang bersangkutan.

\section{DAFTAR PUSTAKA}

Atmoko, Tjipto. (2010). Standar Operasional Prosedur. Jakarta: PT. Bumi Aksara.

Hasibuan, M. S. (2011). Manajemen Sumber Daya Manusia (Edisi Revisi ed.). Jakarta: PT. Bumi Aksara.

Koesmono, H.Teman (2012). Pengaruh standar operasional prosedur Terhadap layanan kesehatan dan Kepuasan Kerja Serta Kinerja Karyawan Pada Sub Sektor Industri Pengolahan Kayu Skala
Menengah Di Jawa Timur: http://sumberdaya manusia.

Manulang, M. (2012). Manajemen Personalia. Jakarta: Ghalia Indonesia.

P. Siagian, Sondang. (2014). Manajemen Sumber daya Manusia. Jakarta: PT. Bumi Aksara

Sedarmayanthi. (2009). Manajemen Sumber Daya Manusia Reformasi Birokrasi dan Manajemen Karyawan Negeri Sipil. Bandung: PT. Refika Aditama.

Sugiono. (2013). Metode Penelitian Kuantitatif, Kualitatif dan $R \& D$, Bandung: CV. ALFABETA.

Sudjana, Nana. (2010). Dasar-dasar Proses Belajar Mengajar. Bandung: Sinar Baru Algesindo.

Sutrisno, E. (2011). Manajemen Sumberdaya Manusia. Jakarta: Kencana.

Yusa Dharmawan, I Made, (2011). Pengaruh Kompensasi dan Lingkungan Kerja Non Fisik terhadap Disiplin dan Kinerja Karyawan Hotel Nikki : http:// sumberdaya manusia. 